\title{
Research on the Construction of College Counselors in the New Era
}

\author{
Lu Limin \\ School of Accountancy, Harbin University of Commerce, Harbin 150028, China \\ llm3187123@sina.com
}

Keywords: Universities, Ideological and Political Work, Counselor, Team Construction

\begin{abstract}
In recent years, the scale of enrollment in Chinese universities has continued to increase, and the tasks faced by ideological and political work for college students and related management work have become more onerous. The social environment and situation in the new era have put forward newer requirements and higher challenges for college counselors' ideological and political education and management services. This article discusses the concrete measures and existing problems in the construction of college counselors, which is of great significance to the construction of college counselors.
\end{abstract}

\section{Introduction}

The report of the 19th Party Congress pointed out that building a powerful education country is the fundamental project for the great rejuvenation of the Chinese nation. We must give priority to the education cause, deepen the educational reform, fully implement the establishment of morality and cultivating the students, and realize the implicit development of higher education (Fan, 2018). Ideological and political work is fundamentally a work of being a human being. We must focus on students, take care of students, serve students, and constantly improve students' ideological level, political consciousness, moral quality, and cultural literacy. Let students become both moral and talented, all-round development of talent (Xi, 2016 and Zhang, 2017). The management of college students in our country is mainly undertaken by the counselors, who play an important role in the teaching management, ideological and political education and life management of colleges and universities. This paper probes into the problems and concrete measures in the construction of college counselors in the new era.

\section{The main problems existing for college counselors at present}

\subsection{Heavy workload and unclear responsibilities of counselors.}

University counselors have dual identities in colleges and universities. They are teachers and administrators. As a teacher, teaching and educating people, student-oriented, guide the healthy growth of students, all-round talent; As a manager, we should strictly carry out the Party's educational policy and the rules and regulations of the school, strengthen the management of the students, complete the tasks assigned by the school's functional departments, and ensure the safety and order of the school's teaching work. The specific work of the counselors includes: taking charge of the ideological and political education and daily management of the students in their classes; paying attention to the ideological and organizational construction of the students' party and caucuses; grasping the style of classes and building the style of study; and helping students with financial difficulties, learning difficulties, and psychological problems; leading students to actively participate in social practice and scientific research and innovation activities; organizing and selecting various advanced individuals, advanced collectives, scholarships, grants, etc. Thus, it can be seen that the counselors should obey the leadership and arrangement of multiple departments and present the working state of "one thousand lines above and one needle below", which leads to the intensification of the work and unclear responsibilities of the counselors. Counselors' work plans are often interrupted by temporary notification from different departments and work efficiency is reduced. 


\subsection{The job burnout of counselors and the blurred development prospect.}

College counselors are the group of teachers who have the most direct contact with college students. The daily work of counselors often shuttles back and forth to receive, process and output information, which consumes a lot of time. The work time and place of counselors are often not fixed, to deal with students' emergencies, long-term stress experience, counselors will not be able to cope with the work smoothly, resulting in physiological, emotional, cognitive, behavioral and other aspects of exhaustion. In the long run, it will greatly thwart the work enthusiasm and creativity of counselors. The college counselors and universities are both management positions and teacher positions. However, in practical work, the promotion space for the two positions is relatively limited.

\section{Specific measures for the construction of college counselors}

\subsection{Strengthen the construction of teachers' morality.}

Teachers are engineers of the human soul and bear the sacred mission. The preacher himself must first open his mouth and channel. College teachers should insist that educators receive education first, strive to become disseminators of advanced ideology and culture, and support the party's governance. They should also shoulder the responsibility of students and guides for students' healthy growth (Li and $\mathrm{Hu}, 2018)$. "study higher for teacher and decency for mirror" Teacher ethics is the moral norm and due morality that teachers should abide by in their education activities ( $\mathrm{Li}$ and Wen, 2018). Teachers' ideal and belief, moral quality and personality charisma directly affect the students' ideological quality, moral sentiment and the cultivation of moral behavior habits. Teachers' ethics can help teachers to coordinate all kinds of relationships in education and teaching, which is a necessary quality for every teacher.

Colleges and universities should take strengthening teachers' ethics and casting the soul of teachers as the standard, improve the ideological and political quality of counselors and the level of professional ethics, and strive to build a high quality team of teachers with high moral integrity, consummate professional skills and full of vitality. So that the counselors become "the model of hard-working learning, the moral cultivation of teachers, and the model of service to students." Counselors should pay attention to teaching by words and examples, and improve the comprehensive quality of teachers and students by setting up a typical and demonstrating guidance.

\subsection{Strengthen basic theory learning.}

By concentrating resources, the school actively encourages the training of teachers and forms the momentum of learning to rush to help; selecting excellent counselors at various levels by observing teaching competitions, and encouraging counselors to apply for projects, and supporting students to participate in the research projects of teachers. It is also necessary to constantly build an incentive teaching platform and organize counselors to improve professional standards through various forms such as collective lesson preparation, on-the-job training, and open classroom teaching Actively carry out network entrepreneurship training, rely on online teaching assistance platform, conduct professional guidance and systematic training for counselors in Internet channel entrepreneurship, cultivate and exercise a team of counselors with higher innovative teaching ability of entrepreneurship education, to form a popularized teaching method suitable for innovative entrepreneurship education. College students as a high quality group will soon enter the society, their ideological and political education is particularly important, counselors as ideological educators should strengthen their own study of political theory. It mainly includes the Marxist theory, the socialist thought with Chinese characteristics in the new era of Xi Jinping, the spirit of the Party's 19th CPC National Congress, the spirit of the national conference on ideological and political work in colleges and universities, and the important documents in the field of ideological and political education of the Party, the state and the college students. Through the study of this kind of political theory, the counselors can adhere to the correct political direction, conscientiously perform the post duties of the counselors, and lay a solid theoretical foundation for the development of ideological and political education. Policies and regulations are the regulations, methods, guidelines, industry 
regulations and regulations formulated by the functional departments. It can guide people's behavior, thus enabling all work to be done in accordance with the most basic requirements and standards. The nature of college counselors directly determines that university counselors must pay attention to and strengthen the study of policies and regulations. For example: related laws and regulations knowledge, party and state and college students ideological and political education important documents and student manuals. For university counselors, timely and accurate mastering of national policies and regulations, and the communication and publication of the regulations to the university students and their implementation within the country are inescapable job duties.

\subsection{Strengthen career planning training.}

The career planning of college students refers to the process of systematic career planning. The quality of career planning has a direct impact on the quality of learning and life in college, employment and directly affects the success or failure of job hunting and even future careers. In recent years, the number of college graduates in China has increased year by year, and college students are facing severe employment situations. College counselors are the most contacted teachers in college life and have a deep understanding of students. Therefore, they play an important role in the employment guidance of college students. College counselors are very important for systematic learning technology training. It is very important for college counselors to carry out systematic training in learning skills, which also requires them to have rich career experience and systematic career coaching.

\subsection{Strengthen mental health training.}

College counselors should deal with two aspects of the relationship, one is the mental health of students, the other is their own mental health. Therefore, systematic mental health training is very necessary Excellent counselors will be under tremendous pressure when they need it, but they must not be left under pressure so that they will suffer physical and mental damage and affect normal work and life. In the new era, educational practice requires that every counselor should improve his personality and enhance his personal charm from the perspective of his own mental health. A successful tutor, in addition to a profound knowledge, must also have a sound personality and noble moral character. The increasingly tense and busy modern life has brought many psychological changes to people. Faced with fierce competition for further studies and pressure from all aspects of society, some counselors are prone to psychological conflicts and depression. College counselors are the specific implementers of school mental health education. If counselors are mentally unhealthy, they cannot correctly understand the students' behaviors, and they can't skillfully deal with student problems. Ultimately, they will lead to inappropriate education behaviors that will have negative impact on college students. With the progress and opening up of society and the socialization of information on the Internet, the entire society is undergoing a period of transition, with multiple cultures intermingled, and the ideological concepts and value orientations have presented a complex and diverse situation. Various social phenomena also have a multi-perspective impact on the minds of college students. The mental health problems of college students are increasingly exposed. The mental problems of college students have become a major obstacle to the happiness of students. The mental health of college students has become a serious social problem, which has posed a new challenge to the mental health education of college students. Therefore, it is urgent to strengthen the mental health education of college students. College counselors are the backbone of mental health education. Therefore, it is of great significance to strengthen the mental health training of college counselors to shape the mental health of college students.

\subsection{Conduct vocational training for counselors.}

The counselor's skill competition includes assessment and testing of basic theoretical knowledge, microblog writing, subject class meetings, heart-to-heart conversations, case studies, self-introduction and presentations. Ability to comprehensively examine counselors' language skills, activity planning and implementation skills, ideological education and psychological counseling skills, and daily transaction processing skills. professional skill. At the same time, the competition of 
counselors' skills can also promote the exchange of counselors' work, enhance the ideological realm and enhance the vocational skills; the various skill competitions, which are close to the practical work of counselors, can broaden the horizons of students' work and expand their working ideas. To further improve the work of counselors has an important role in promoting.

College counselors are both mentors for the healthy growth of college students and guides for career planning for college students. The role of the instructors in education cannot be replaced by anyone in institutions of higher learning. Colleges and universities should make great efforts to set up a team of counselors with "high quality and strong ability", combine ideological and political education with career planning and guidance, and cultivate and build excellent counselors through the quality and ability competition of counselors. In order to promote and enhance the overall level of ideological and political education for college students. The construction of college counselors has entered a good stage of development, but it is still a long-term and complex task.

\section{Acknowledgements}

This work was financially supported by Harbin University of Commerce Ph.D. Research Startup Project (14LG32).

\section{References}

[1] Fan Guorui. Adhere to the People-centered Education Policy Research. Journal of East China Normal University, 2018 (3), p.27-28.

[2] Xi Jinping. Putting Ideological and Political Work through the Whole Process of Education and Teaching, Creating a New Situation in the Development of Higher Education in China. People's Daily. 2016(1), p.1.

[3] Zhang Zi. Ideological and Political Work is Fundamentally a Work of Human Beings. Ideological Education Research, 2017 (5), p.7-10.

[4] Li Meixi, Hu Xiaohong. New Thoughts on Improving the Teaching Quality of Ideological and Political Theory Courses in Colleges. Continuing Education Research, 2018 (5), p.82-87.

[5] Li Qingsong, Wen Qian. Thoughts on Higher Education Work in the New Period. Education Modernization, 2018 (17), p.169-170. 